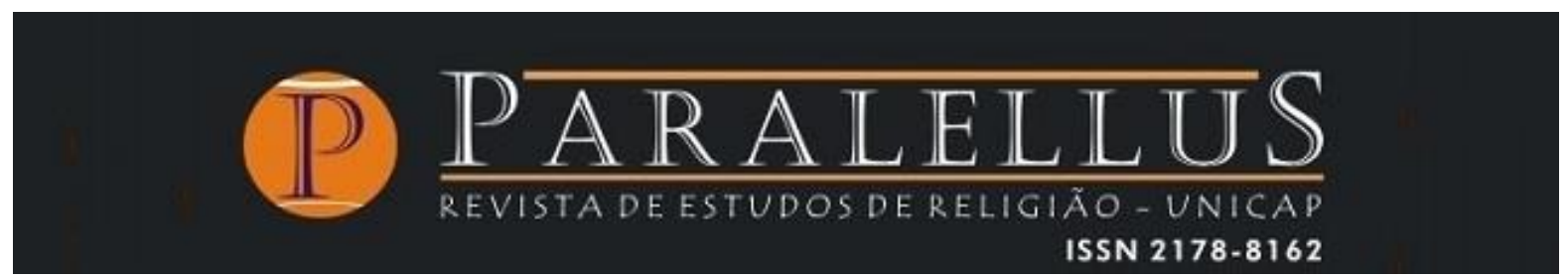

Volume 12 - Número 30

DOSSIÊ: A SABEDORIA NAS SAGRADAS ESCRITURAS

doi: 10.25247/paralellus.2021.v12n30.p353-367

\title{
INTERPELACIÓN BÍBLICA Y RELATOS AMERICANOS
}

\author{
BIBLICAL INTERPELLATION AND AMERICAN STORIES
}

\author{
Prof $^{a}$ Drª Rita Maria Gomes \\ Prof. Diego Irarrazával **
}

\section{RESUMEN}

El presente artículo tiene como objetivo considerar sabidurías en diversos pueblos y sus significados polisémicos. Son considerados varios aportes bíblicos e importantes creencias y escritos en regiones de Latinoamérica. Es utilizada la metodología de examinar realidades y sus interpretaciones, con respaldo bibliográfico. El texto sigue los pasos siguientes: en la primera parte se considera la sabiduría en Israel, tanto su comprensión más general como líneas de crítica presente en la propia Escritura. La segunda parte considera tradiciones sapienciales y rituales, en sectores indígenas, mestizos, negros. Todo este recorrido indica como lo sapiencial es un gran componente de la transmisión de vivencias religiosas y de horizontes de esperanza. Ello habla directamente al corazón de personas y pueblos a lo largo de la historia. Aquí es crucial la Palabra que da vida, y que tiene mediaciones culturales.

Palabras Claves: Sabiduría bíblica; Popol-Vuh; Guadalupe; Mariama; Mestizaje.

\section{ABSTRACT}

This article considers wisdom within people's journeys of life, and the gamut of its meanings. Several biblical resources are considered, and also ways of faith and knowledge in regions of

\footnotetext{
* Possui graduação em Bacharelado em Filosofia pelo Instituto Teológico e Pastoral do Ceará (2004) atual Faculdade Católica de Fortaleza, graduação em Bacharelado em Teologia pela Faculdade Jesuíta de Filosofia e Teologia (2007); mestrado (2011), e doutorado (2017) com estágio na Université Catholique de Louvain (Bélgica).

** Profesor de teología, y vicario parroquial en Santiago. Presbítero, Congregación de Santa Cruz. Coordinó el Instituto de Estudios Aymaras (1981 - 2004), y la Asociación de Teologos/as del Tercer Mundo (1995 -2006). Miembro del comité editorial de CONCILIUM(2005 - 2017).
} 
the Americas are examined. Understanding of events and traditions, different interpretations, and bibliographical items, are taken into account. This essay follows the following steps: in the first part, wisdom in Israel is considered, both its more general presentation of wisdom and internal critical contributions (particularly in Job and in Qohélet). The second part (of this essay) deals with elements of wisdom and ritual, among indigenous, mestizo, and afro-american populations. Both a reading of biblical texts and an examination of popular traditions have their particular challenges. Wisdom includes communication of religious traditions and hopeful living. It speaks directly to the hearts of people throughout history. The Word is life-giving and it has cultural mediations.

Keywords: Biblical wisdom; Popol-Vuh; Guadalupe; Mariama; Hybrid cultures.

\section{INTRODUCCIÓN}

La sabiduría es un fenómeno encontrado en todas las civilizaciones y es caracterizada por el modo propio con que cada pueblo desarrolla sus códigos de ética y presenta los fundamentos religiosos de sus leyes. Así, las prácticas del cotidiano quedan entramadas con el sentido del divino y por eso es habitual que se encuentre, en los escritos sapienciales de los pueblos más diversos, relatos cosmogónicos en que se entrelazan la generación del cosmos y la creación del ser humano.

En este texto se trata del amplio tema da la sabiduría a partir de dos tradiciones principales: la Sagrada Escritura judía-cristiana y algunos relatos actuales amer-indionegro-mestizo. Lo último trae consideraciones a respeto de pueblos indígenas mesoamericanos y de los afrodescendientes de Brasil. En la primera parte el foco es la relación intrínseca entre la práctica y la comprensión de Dios que tiene el hombre bíblico y cómo la vida cotidiana es determinante para el entendimiento del actuar de Dios en favor de los humanos. En la segunda parte, el texto se vuelve enteramente para las experiencias de los pueblos de matriz indígena y negra a partir de textos y canciones religiosas que, por su vez, revelan su visión de Dios y de la actuación divina, por lo tanto, son también sabiduría que relaciona el vivir con la divinidad.

En cada una de las partes son considerados tres puntos. En la primera parte se trata de la sabiduría en Israel como una forma particular de expresión de la experiencia que Israel hace de Dios para después ver como la sabiduría práctica, o sea, la vida cotidiana se muestra un parámetro de verificación del actuar de Dios. Por fin, se considera los casos especiales de los libros de Job y Eclesiastés en vista de la 
demostración de la crítica de los autores bíblicos de la teología tradicional por medio de la consideración de la experiencia.

En la segunda parte, se hace la reflexión acerca de la sabiduría de la población amerindia-negra. En el primer punto se hace una presentación, a partir de los textos sagrados de los pueblos mesoamericanos, de la generación de la vida cósmica. En el segundo punto, se piensa el carácter impugnador de la iconografía al tener como punto de partida el hibridismo atestiguado en culturas como las de México y de Brasil, el guadalupismo y la virgen negra Aparecida. En eso se revela el vínculo estrecho entre la experiencia del divino y su expresión cultural y cultual. En el tercer y último punto, se abre espacio para seguir el dialogo.

\section{LA SABIDURÍA POPULAR EN LAS SAGRADAS ESCRITURAS}

\subsection{La sabiduría como expresión de la experiencia de Dios en Israel}

El tema de la sabiduría solo puede ser pensado en relación directa con su contrario: la necedad. Además, este tema es desarrollado del punto de vista del vocabulario considerando termos positivos y sus contrarios. Es lo habitual para hablar de determinados temas empezar por el vocabulario propio o por la semántica. La noción de sabiduría, cuando si piensa exclusivamente en Israel, no puede ser pensada solamente desde la palabra "sabiduría" sino más por el grupo de términos hebreos que abarcan una amplia variedad de situaciones.

En los textos bíblicos clasificados cómo escritos sapienciales encontramos los términos derivados de la raíz hebrea jkm, jokmah (sabiduría) e jakan (sabio). Los substantivos derivados de la raíz byn, bynah o tebunah (entendimiento, inteligencia) y aun muchos otros semánticamente afines (CARRASCO, 1997, p. 545). Eso significa que el tema es más complejo que lo que se pueda pensar en la primera mirada. En los textos bíblicos no hay una definición de la sabiduría en los moldes griegos a los cuales el Occidente está acostumbrado. Es la experiencia vivida y compartida que revela lo que los israelitas piensan ser sabiduría, o sea, es la vida vivida cotidianamente que dice lo que es la sabiduría y lo que es la necedad. En ese sentido es ejemplar el banquete de la Doña Sabiduría y de la Doña Necedad en el libro de Proverbios (ZAPATA, 2009, p. 407). 
La sabiduría de Israel reflexionada como un conjunto de textos literarios bebe de los escritos de pueblos más antiguos del entorno de Israel. Con eso tenemos un tipo de texto muy particular direccionado para la instrucción de los futuros gobernantes, reyes o sus colaboradores más cercanos. Pero, en Israel, la instrucción es tanto para los futuros gobernantes cuanto para las personas en general porque la instrucción es torah, enseñanza o simplemente instrucción (DARDER, 2004, p. 15).

Para los israelitas, la Torah o Pentateuco es la instrucción para la vida conforme el deseo de Dios, o sea, la conformación con la voluntad de Dios en todos los ámbitos de la vida. La base de esa comprensión es algo muy simple, es la consciencia de que una vez que ellos son el pueblo de Dios, ellos no pueden andar de cualquier modo. Hay una práctica, una forma de llevar su vida que debe revelar su Dios. Aunque sea fuertemente enmarcada por los textos sapienciales de Egipto y Babilonia (MESTERS, 2000, p. 25-27), Israel desarrolla su sabiduría propia en la que vincula la experiencia vivida con la revelación de Dios y su creación, en la cual presenta su cosmogonía.

Los textos sapienciales más antiguos de Israel revelan una preocupación por la vida en su sencillez, bien cómo la exposición de esa sabiduría práctica es pasada también de manera sencilla a través de proverbios de dos miembros en paralelismos que son nombrados paralelismos sinonímicos, antitéticos y sintéticos (ASENSIO, 1994, p. 112113) ${ }^{1}$. Esta forma de expresar la sabiduría es bien popular porque ayuda la memoria y fácilmente si retiene su enseñanza. Ese modo de enseñar es tan poderoso que aun hoy día está presente en nuestras culturas cómo una forma poderosa de educación de los hijos para la vida.

Los primeros proverbios son dedicados a la instrucción a respecto de la educación de los hijos para una buena conducción en la vida (SILVA, 2020, p. 302). Por eso, en lo libro de los Proverbios muchas secciones empiezan por la formula "escucha hijo mío" o simplemente "hijo mío"2 y siguen orientaciones sobre cómo portarse a la tabla, en

1 Ejemplos de los paralelismos: $\operatorname{Pr}$ 15,30 - Una mirada luminosa alegra el corazón, una buena noticia reanima el vigor. Ese es un proverbio de tipo sintético. Pr 12,5 - Las intenciones de los justos son equidad, los planes de los malos, son engaño. Ese es un proverbio de tipo antitético. Los paralelismos sinonímicos son raros en lo libro de los Proverbios, pero mui comunes en los Salmos. Un buen ejemplo es el SI 8,4 - ¿qué es el hombre para que de él te acuerdes, el hijo de Adán para que de él te cuides?

$2 \operatorname{Pr} 1,8.10 .15 ; 2,1 ; 3,1.21 ; 4,10.20 ; 5,1.20 ; 6,1$ etc.

Paralellus, Recife, v. 12, n. 30, mai./ago. 2021, p. 353-367 
sus finanzas $(\operatorname{Pr} 6,1)$, en su trabajo $(\operatorname{Pr} 6,6-11)$, en sus relaciones con el que consideras malas compañías ( $\operatorname{Pr} 5)$, entre tantos otros temas del día a día.

\subsection{La sabiduría práctica: parámetro de verificación de la acción de Dios}

Israel concibe la vida humana como un espejo que revela la adecuación de las acciones humanas a la voluntad de Dios, por eso la mentalidad israelita desarrolló un principio básico de verificación de la realidad según lo cual el que hace el bien recibe bienes de la parte de Dios y los que hacen el mal reciben cosas malas. Esto ocurre porque el israelita tiene una visión de mundo en lo cual existe una orden inscrita en la naturaleza, tanto cósmica cuanto humana, así que si él se adecua à esa orden todo curre bien y si non todo camina para la destrucción (CARRASCO, 1997, p. 119-120). La afirmación tradicional de que la buena acción humana garantiza bienes terrenos fue llamada "teología de la retribución".

Según esa teoría, o "teología", la adecuación a la voluntad de Dios, el vivir una vida justa conforme el derecho y la justicia, llevaría naturalmente a una vida larga, con muchos hijos y muchos bienes materiales. Pr 4,10 atestigua la estrecha relación de la sabiduría con una vida larga al decir escucha, hijo mío, recibe mis palabras, y los años de tu vida se te multiplicarán. Pr 3,1-2, entre otros, atesta la relación de la sabiduría con los bienes materiales diciendo Hijo mío, no olvides mi lección, en tu corazón guarda mis mandatos, pues largos días y años de vida y bienestar te añadirán. Muchos son los textos a lo largo de la Escritura que demuestran la grande cantidad de hijos como señal de la bendición divina. Así, vida larga, muchos hijos y riqueza son señales de las bendiciones divinas y una clara demostración de la sabiduría de aquel hombre o mujer. El contrario de eso es la señal de la maldición, pues $\operatorname{Pr} 10,22$ atesta que la bendición del Señor Dios es que enriquece al decir la bendición de Yahveh es la que enriquece, y nada le añade el trabajo a que obliga. De muchos modos el libro de Proverbios va haciendo un contrapunto entre el sabio y el necio, el justo y el injusto, reforzando la idea de que las cosas buenas son recompensas divinas por actuar conforme la sabiduría.

\subsection{Job y Eclesiastés: la sabiduría tradicional en crisis}


La perfecta adecuación de buenas acciones y bendiciones divinas ni siempre es percibida en la vida. Los libros de Job y Eclesiastés son la antítesis de la afirmación tradicional. El libro de Job trae la historia de un personaje nombrado Job que tiene muchos bienes materiales, muchos hijos, ya adultos lo que dije que él es un hombre mayor. Todo parece corresponder a la tesis tradicional, pero la historia cambia drásticamente y Job pierde todo, los bienes, los hijos y es acometido de una enfermedad cruel. A partir de ese punto empieza una parte distinta en lo libro en lo cual tenemos varios diálogos de Job con otros personajes que intentan a toco costo convencer a Job que él ha pecado y por eso ha sido castigado por Dios. El personaje Job a la vez contesta que él no ha pecado. Es su propia vida que sirve de argumento mayor contra la tesis tradicional. Él cuestiona la inadecuación de la afirmación teológica tradicional porque ella no corresponde a la experiencia de la vida. Más una vez, es la vivencia cotidiana que lleva el autor bíblico a repensar sus afirmaciones. Es la misma idea que aparece en el Evangelio cuando Jesús afirma el sábado ha sido instituido para el hombre y no el hombre para el sábado (Mc 2,27). Es la vida que nos revela como Dios actúa. El sufrimiento de Job es el contra-argumento de la teología de la retribución tal como afirmada por los "amigos" de Job.

El libro de Job, bien como el de Eclesiastés, revela que la acción divina es muchas veces incomprensible para nosotros. Pues, el sufrimiento del justo es confrontado con el silencio de Dios. Una vez más la experiencia de Job se acerca de la de Jesús, pues en el momento más angustiante de la vida de Jesús él experimenta el silencio de Dios. Pero atención, silencio no quiere decir ausencia, pues tanto Job cuanto Jesús terminan por profesar su entera confianza en el juicio de Dios.

En el libro de Eclesiastés encontramos una contestación de la tesis tradicional un poco distinta, pues non se basa en la historia de vida de un personaje específico sino en un cuestionamiento más general. El Eclesiastés cuestiona toda la realidad perceptible con una nota que puede sonar negativa: vanidad de vanidad todo es vanidad. También lo hace al cuestionar ¿qué provecho tira el hombre de toda la fatiga de su trabajo? o aún en la afirmación no hay nada de nuevo debajo del sol.

Al observar la naturaleza y la vida cotidiana, él comprende que existe una especie de repetición continuada de los ciclos de la vida y si pregunta si eso no es una ausencia 
completa de sentido. El Eclesiastés cuestiona todo "abajo del sol", la administración de la justicia, el uso del dinero, la suerte del hombre etc. Con ese último tema, el Eclesiastés va a considerar algo que Job no se atreve a hacer. Eclesiastés considera de igual modo el fin del hombre y el fin de los animales al afirmar el hombre y la bestia tienen la misma suerte: muere el uno como la otra; y ambos tienen el mismo aliento de vida. En nada aventaja el hombre a la bestia, pues todo es vanidad (Ecle 3,19). Cuanto a los hombres, él afirma que todos van a tener el mismo fin, los justos y los injustos, el bueno y el malo, el puro y el impuro (Ecle 9,1-2) etc.

Pero, el texto que más claramente cuestiona la tesis tradicional es Ecle 6,1-6.

Hay otro mal que observo bajo el sol, y que pesa sobre el hombre: Un hombre a quien Dios da riquezas, tesoros y honores; nada le falta de lo que desea, pero Dios no le deja disfrutar de ello, porque un extraño lo disfruta. Esto es vanidad y gran desgracia. Si alguno que tiene cien hijos y vive muchos años, y por muchos que sean sus años, no se sacia su alma de felicidad y ni siquiera halla sepultura, entonces yo digo: Más feliz es un aborto, pues, entre vanidades vino y en la oscuridad se va; mientras su nombre queda oculto en las tinieblas. No ha visto el sol, no lo ha conocido, y ha tenido más descanso que el otro. $Y$ aunque hubiera vivido por dos veces mil años, pero sin gustar la felicidad, ¿no caminan acaso todos al mismo lugar?

Para el Eclesiastés no hay verdaderamente diferencia entre lo que vive muchos años, posee muchas riquezas y muchos hijos y el aborto. Es una afirmación chocante para aquel momento y quizás aún hoy día. Pero, es una manera de decir que Dios ni siempre actúa como nosotros esperamos. Dios tiene su propia manera de actuar y de revelarse. Es en la observación de la vida cotidiana, en lo ejercicio diario del amor al prójimo y en el ejercicio de la justicia que vemos la manifestación de Dios y es en el confronto con la vida que descubrimos el hablar y el actuar de Dios. De ese modo, podremos corregir nuestras teologías. Es en ese sentido que los más diversos pueblos engendran textos y tradiciones sapienciales en los cuales transmiten su comprensión de Dios y de su actuar y también del ser humano.

\section{SABERES EN LA POBLACIÓN AMER-INDIA-NEGRA}

En los milenios del caminar humano hay diversos modos de entender procesos con sus crisis y clamores. Lo indicado en escritos bíblicos, y lo expresado en tradiciones americanas, no es homologable; pero sí es aleccionador como encaran 
incertidumbres. Al transitar entre luces y tinieblas la humanidad confronta y resuelve simbólicamente sus desafíos. Por ejemplo, relatos míticos explicitan el don de vivir y también ahuyentan catástrofes; ello lo palpamos en relatos mesoamericanos y en ceremonias afro-brasileras. Lo vemos con ojos de las ciencias sociales, y además lo examinamos con fe; existen distintas rutas de sacralidad e invocación a Dios.

Otra cuestión crucial es discernir contemporáneos artefactos y héroes con pretensiones icónicas. Esto ocurre en torno a mercancías, tecnologías, espectáculos mediáticos, deportes, y tanto más. La labor bíblica y eclesial está atenta a sus propias fuentes y celebraciones, y a la vez indaga fenómenos en esta época de postsecularismo y de ambivalente espiritualización.

\subsection{Generación de vida cósmica}

Intuitivamente la población reconoce y reclama sobrevivir dignamente; así lo indican dichos tales como: a Dios rogando y con el mazo dando, haz el bien y no mires a quien, Dios los cría y el diablo los junta, últimos serán primeros; en estos y otros lenguajes del pueblo resuenan verdades bíblicas. De modo sistemático, pueblos mayas, andinos, amazónicos, caribeños, afroamericanos, son portadores cada uno a su manera de enseñanzas cotidianas y de relatos cosmogónicos ${ }^{3}$. Es un entender cómo tratarnos bien y cómo evitar males, y explicar por qué existen ríos, montañas, vegetales y animales, humanidad y entidades sagradas. Todo procede del silencio, del verde y azul, de circunstancias. Hay mitología de los orígenes. Un denominador común es ofrecer explicaciones de catástrofes y de capacidades. Son representaciones de dolor y de esperanza; cada manifestación suscita estudios interdisciplinarios. En qué sentido hay revelación universal, con mediaciones socioculturales. El saber autóctono merece ojos críticos.

3 Veanse Claude Levi-Strauss, Mitológicas, Mejico: FCE, 2016; Ortiz, Alejandro. Mitologia amerindia, Madrid: Trotta, 2012; Roger Bastide, The african religions of Brazil, New York: J. Hopkins University, 2007; Rita Segato, "La religiosidad candomblé", Perfiles Latinoamericanos FLACSO, n² 2, 1993, 133164; Michael Sells, The mystical language of unsaying, Chicago: University of Chicago, 1994. Además, simposios de teología india desentrañan el sentido tradicional (oral y ritual) de estar y transitar en la Casa Común, dónde abunda tanto la maldad como la bondad; véase $\mathrm{V}$ Encuentro, La fuerza de los pequeños, Cochabamba: Verbo Divino, 2008. Estos encuentros incentivan la lectura crítica de mitos tradicionales. 
Vale detenerse en el Popol Vuh k'iché de mediados del siglo 16, que algunos llaman "la biblia maya", y que hoy tiene significación mundial". Me disculpan unas breves anotaciones, y remito a obras de Sam Colop y Adrián Recinos. Sólo anoto elementos en orígenes del universo, y en una plegaria.

Los progenitores Tepeu y Gucumatz "entraron en plática acerca de la creación y la formación de nuestra primera madre y padre. De maíz amarillo y de maíz blanco se hizo su carne; de masa de maíz se hicieron los brazos y las piernas... los cuatro hombres que fueron creados"; más adelante es registrado como

se acordaron de la palabra del Creador y Formador, del Corazón del cielo, del Corazón de la tierra... y elevaban sus ruegos: danos nuestra descendencia, nuestra sucesión, mientras camine el sol y haya claridad. Que amanezca. Que llegue la aurora. Danos muchos buenos caminos, caminos planos. Que los pueblos tengan paz, mucha paz, y sean felices, y danos buena vida y útil existencia (RECINOS, 1976, p. 104 y 109).

Es invocada una deidad plural y relacional, y es explicada la gestación de la humanidad desde el maíz: el 'pan' mesoamericano. La invocación a las deidades tiene sellos históricos y relacionales para vivir bien.

Un modo de acercarse a esta obra monumental es diferenciar secciones cosmogónicas (que provienen del siglo 4 de nuestra era), relatos de los jóvenes gemelos, y luego secciones históricas de la población k’iché (de los siglos 13 al 16). Como es sabido, es recogida la honda y compleja vivencia espiritual, y luego la fundación de pueblos hasta la conquista; vale decir, espiritualidad y acontecer conflictivo del pueblo k'iché con sus deidades del bien y del mal.

Es admirable una propuesta pedagógica en Guatemala, coordinada por Ricardo Falla, que tiene cuatro dimensiones: experiencia de Dios, visión crítica, conciencia agradecida, historia. La meta es "ver la esencia del pueblo k'iché... para transformar el mundo hacia la justicia, la verdad y la paz, como lo vimos en el código ético de la

4 Las mejores transcripciones son las de Sam Colop (Popol Vuh, Guatemala, 2011) y de Adrián Recinos (Popol Vuh, Mexico 1976), Véanse tambien Carlos Lopez, Los Popol Wuj y sus epistemologás, Quito: Abya Yala, 1999; Miguel León Portilla (ed.), Native mesoamerican spirituality, New York: Paulist Press, 1980; Mercedes de la Garza, Rostros de lo sagrado en el mundo maya, Mexico: Paidós, 1998. 


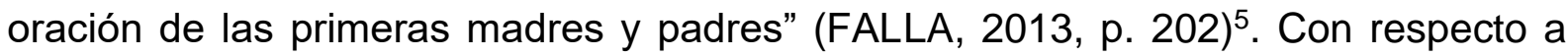
expresiones bíblicas y a las "vicisitudes de los pueblos mayas desde su lugar de origen hasta su establecimiento en Guatemala... donde desarrollarían una de las más elevadas civilizaciones" es probable que "el indio transcripto haya insertado algunos pasajes bíblicos con el propósito de atenuar el matiz 'pagano' y poner el documento a salvo de la mano destructora de los españoles" (CORTEZ, 2010, p. 11). En cualquier caso, las coincidencias temáticas e intertextualidades indican el compartir simbólico en la humanidad. A la vez, llama la atención la pluralidad divina y el imaginar 4 primeros individuos. Además existen cuatro dimensiones del universo con sus colores rojo, negro, blanco, amarillo.

En lenguajes míticos, y sobretodo en certezas modernas, abundan los fundamentalismos, para aplacar "una angustia vital, una seguridad sin fisuras con un líder guía infalible, o unos textos sagrados" 6 . La vida cósmica es imprediscible; y la fragilidad humana no merece refugiarse en absolutos que caducan.

\subsection{Iconografia con carácter relacional e impugnador}

Las simbólicas del mestizaje y de la negritud caracterizan la humanidad americana, que tienen iconografías enraizadas en la fe mariana. En la historia eso aglutina y diferencia a la multitud: "la virgen de Guadalupe en la vida cotidiana de los mexicanos va mucho más allá de la fe, es un acto de identidad nacional" (ARNAL, 2010)7. polivalente guadalupismo contemporáneo tiene hondas raíces mestizas. El Nican Mopogua de 1566 proviene de un "cristiano sincero, familiarizado con muchos aspectos del antiguo pensamiento nahuatl" que transmite el mensaje guadalupano "en verdad soy yo, su madrecita de Él, Dios verdadero, dador de vida, inventor de la gente, del cerca y del junto"; esto caracteriza la espiritualidad nahuatl, ya que el trabajador llega a la "tierra florida ... y sabe que la noble señora celeste es su Madrecita

5 Siendo intercultural la obra de. R. Falla puede enfatizar "más la experiencia que los conceptos y la espiritualidad más que la religión" (p. 202). Es evitada la unilateralidad.

6 Comunicación personal, 4/3/2021, por Herbert Alvarez, teólogo de Guatemala, que investiga relatos tradicionales y mitos sociales y tecnológicos contemporáneos. Lo llamado 'sagrado' requiere autocrítica.

7 Arnal añade: "el guadalupanismo ha significado muchas cosas, desde el pilar donde pivota la Independencia, hasta los goles que marca para la selección mexicana de fútbol.... la fe en la virgen futbolera no disminuye ni en las gradas ni en los vestidores.... la Guadalupe apadrina la independencia de México, la guerra santa cristera, el fútbol...". Uno a menudo escucha: soy mexicano, soy guadalupano. 
compasiva, es Tonantzin Guadalupe" (LEÓN-PORTILLA, 2002, p. 87 y 90)8. La iconografía mestiza es bellamente invocada como Tierra Florida; pero, de hecho allí coexisten pocos pudientes y muchísimos discriminados cuyos vínculos con Cihuacoatl -diosa madre- son descalificados.

Una mirada de género anota que "el mestizo niega su descendencia india... y busca a la madre perfecta en la virgen María"; además señala "mitos del mundo mestizo e indoamericano [que $]^{9}$ dan cuenta de la encarnación de la divinidad en hombre a través del cuerpo de la mujer... para hacer posible esa divinización masculina" (PALMA, 1990, p. 18). Otros estudios lamentan que la supremacía androcéntrica tiene como contraparte una ahistórica representación de María. El 'marianismo' elogia rasgos espiritualistas, y a la vez respalda un 'destino' sufriente y sacrificial de mujeres. Además, es incentivado el turismo religioso, la mercancía simbólica, el pietismo que beneficia al pobre. Ello -de varias maneras- contamina experiencias del pueblo creyente.

Sin embargo, la tradición ibero-americana conlleva cierta resistencia a racismos sociales e intolerancias religiosas. Esto sobresale en torno a Mãe Nossa Senhora, encontrada en el Rio Paraíba (1717) por pescadores como una imagen de arcilla, y restaurada luego del atentado $(1978)^{10}$. Su negritud tiene resonancia universal e impugna el blanqueamiento de cristiandad. Esta breve reseña sólo menciona dos logros contemporáneos. La "Missa dos Quilombos" de P. Casaldaliga, P. Tierra, M. Nascimento, y la proclama antiviolencia "Mariama” del queridísimo Helder Camara. Todo eso constituye una Buena Nueva sin exclusión.

Se trata de un lenguaje mítico y poético de carácter colectivo y militante. La vigorosa Missa dos Quilombos, comienza con su "Em nome de Deus" y concluye con el coro:

"Iya, Iya, ó Mãe do Bom Senhor. Maria mulata. Morena Formosa. Mãe do Santo. Comadre de tantas. Forte do calvário. Saravá da páscoa de

8 Recomiendo además al historiador británico David Brading, La Virgen de Guadalupe. Imagen y Tradición. Mexico: Taurus, 2002; y al teólogo mejicano Clodomiro Siller, Para comprender el mensaje de Maria de Guadalupe, Buenos Aires: Guadalupe, 1989.

9 Este que no se encuentra en la cita, pero fue introducido para una mejor comprensión.

10 Véase Julio Brustoloni, Historia de Nossa Senhora Aparecida, Aparecida: Santuario, 2010; Valdivino Guimarâes, Iconografia de Aparecida, Sao Paulo: Paulus, 2016; en lo teológico: Clodovis Boff, Mariologia Social, Sao Paulo: Paulus, 2006; en lo interdisciplinar: Carlos A. Steil, C.L. Mariz, M.L. Reesink (org.), Maria entre os vivos, Porto Alegre: UFRGS, 2003 (con estudios locales y regionales de 'apariciones"). 
ressurreição... que derruba os ricos e os grandes; ergue os submetidos... Samba na alegria dos pés congregados. Encoraja os gritos. Acende os olhares... desce novamente às redes da vida do teu povo negro, Negra Aparecida" (SCHMIDT, 2017). ${ }^{11}$

Es una simbólica profética y alucinante, que uno siente hondamente. Además, el frágil y tenaz dom Helder Camara ha invocado a Mariama (que fue añadido a la difusión del clamor de los Quilombos con el carismático Milton Nascimento).

\begin{abstract}
"Mariama, Mãe dos homens de todas as raças, de todas as cores, de todos os cantos da Terra. ... Basta de injustiça. Basta de alguns tendo que vomitar para comer, e 50 milhões morrendo de fome num só ano. Basta de uns com empresas se derramando pelo mundo todo, e milhões sem um canto onde ganhar o pão de cada dia. ... Nada de escravo de hoje ser senhor de escravo de amanhã. Basta de escravos. Um mundo sem senhor e sem escravos. Um mundo de irmãos. De irmãos não só de nome e de mentira. De irmãos de verdade, Mariama"12.
\end{abstract}

Este clamor contra cualquier violencia coincide con la música final de la misa de los quilombos, una "marcha de procesión y de esperanza". Tanto la iconografía mestiza de Tonantzin-Guadalupe, como el festejo con la muy venerada Mariama-Negra, registran imaginarios que nos humanizan. Lamentablemente persiste un devaluar la raigambre indo-mestiza-negra.

\title{
3.3 Cuestiones al seguir dialogando
}

Al desentrañar herencias sapienciales, que nos llegan por lecturas bíblicas, y también por la historia de este continente, se aprende a no sacralizar ni la una ni la otra. Más bien, uno aprecia más la casa cósmica y la convivencia humana, siempre amenazada por poderes discriminatorios. En cuanto a entender el origen o generación del universo, la tradición maya -en el Popol Vuh elaborado durante siglos- ayuda a reconocer la corporeidad desde el maíz, y a dar gracias a quienes generan vida. También somos convocados -mediante una rica experiencia pedagógica en

11 Beatrice Schmidt, Letra, música, performance e memoria do racismo na Missa dos Quilombos, Brasília, 2017. https://repositorio.unb.br/bitstream/10482/24420/1/2017_BeatrizSchmidtCampos\%E2\%80\%8B.pdf (recuperado 27/2/2021).

12 Unos fragmentos de (recuperados el 27/2/2021). www.youtube.com/results?search_query=helder+camara+mariama 
Guatemala- a reconstruir mitos y ritos relevantes para el mundo de hoy. De modo especial, hay que ser fieles al medio ambiente y a la humanización.

Con respecto a ambivalentes simbologías, se anotó la de Guadalupe enmarcada por el nacionalismo mexicano, y la de Aparecida que resiste al racismo pero no sobrepasa la blanqueada cristiandad. Sin embargo, poblaciones mesoamericanas y afrodescendiente, al vincularse a la tierra florida y mestiza, y a una profética MariamaNegra, ofrecen diseños imaginarios de un mundo nuevo. Además, evocan opciones no androcéntricas que sintonizan con el Evangelio de Jesús y su Madre que claman liberación.

Tomando en cuenta tradiciones ibero-americanas vale preguntar su importancia ante inmensos desafíos actuales ${ }^{13}$. ¿Son como raíces en movimiento? ¿Cómo entretejer esperanzas realistas? Dicho brevemente, sufrimos el escenario en que todo es mercancía y es también espectáculo; alimentan deseos insaciables. Abundan mitos seculares y religiosos; que carecen de autocrítica; $y$, deslumbran a multitudes y a instituciones ensimismadas. Soportamos un colapso civilizatorio y medio ambiental. La revolución digital conlleva ilusiones de felicidad efímera. Ante tantísima pregunta e inquietud por el cambio de época, la relacionalidad ética y la celebración evangélica son relevantes criterios para encarar cualquier situación humana.

A fin de cuentas, lo sapiencial no es palabrería ni es un absoluto. Más bien, los lenguajes míticos y rituales apuntan a la vida y a la comensalidad. Lo llevan a cabo con la sensibilidad expresada en múltiples tradiciones espirituales y seculares de la humanidad, y comunicada en el acontecer Jesuánico: la preferencia hacia quienes tienen hambre y sed de justicia.

\section{CONSIDERACIONES FINALES}

\footnotetext{
13 Véanse Rafael Diaz-Salazar, S. Giner, F. Velasco, eds., Formas modernas de religión, Madrid: Alianza Editorial, 2001; Martine Segalen, Ritos y rituales contemporáneos, Madrid: Alianza, 2005; Maximiliano Salinas, Gracias a Dios que comí, El cristianismo en lberoamérica y el Caribe. Siglos XVXX, Mexico: Dabar, 2000; Alicia Juarez, Ramiro Gomez, Hierofanías de lo cotidiano, Mexico: Senda Libre, 2018; Ivoni Richter, Keila Matos (org.), Mitologia e literatura sagrada, Goiania: PUC Goias, 2009; Roberto Cipriani, Eleta, Paula, Nesti, Arnaldo (org.), Identidade e mudança na religiosidade latino-americana, Petrópolis: Vozes, 2000.
} 
Nuestra responsabilidad reflexiva y pedagógica cuenta con recursos bíblicos y con polisémicas narrativas americanas. Dada la envolvente industria cultural y la acelerada revolución tecnológica, vale continuar asimilando recursos y relatos emancipadores. Palabras en situaciones de crisis -como en Job y en Eclesiastés- y la calidad sapiencial israelita constituyen -tanto en el pasado como el presentemediaciones del acontecer de Dios. De modo similar, al retomar tradiciones mayas, mejicanas, afro-brasileras, puede palparse como el amor de Dios acompañó y continúa interpelando el caminar de los pueblos. No son recursos homologables. Cada saber tiene sus contextos y desafíos. Además, sobresale el implementar un vivir de modo interactivo y espiritual, impugnador de injusticias y acogedor de la verdad.

Cada persona y comunidad está capacitada para continuar bebiendo la buena agua bíblica y las tradiciones vigentes en nuestro continente. Las herencias bíblicas y las vivencias de cada pueblo amado por Dios nos permiten desentrañar la manifestación divina en toda la historia humana. Dios ha sido y es amable con la humanidad a lo largo de siglos y siglos. Tiene sus maneras de actuar y revelarse. Al sopesar experiencias propias y de otros pueblos, la comunidad cristiana redescubre tradiciones sapienciales, y puede apreciar tejidos espirituales del mundo. En nuestros contextos sobresale el saber acumulado durante siglos, narrativas creyentes y celebraciones -como la de Guadalupe-, y clamores afro-americanos -como el de Mariama. Todo esto nutre la labor teológica y redimensiona la actividad eclesial. La sensibilidad de nuestros tiempos y la creatividad sapiencial y celebrativa de sectores marginados permiten releer la tradición judeo-cristiana y el desenvolvimiento actual de la fe. Los saberes del pueblo son dadores de vida.

\section{REFERENCIAS}

ARNAL, Ariel. La Guadalupana. Socio-política mexicana desde la iconografía religiosa. Estudios Políticos, n² 21, 2010, p. 101-112.

ASENSIO, Victor Morla. Libros sapienciales y otros escritos. Estella: Verbo Divino, 1994.

A BÍBLIA de Jerusalén. Bilbao: Desclée, 1975.

CARRASCO, Joaquín Menchén. Comentario al Antiguo Testamento II - Escritos sapienciales. Estella: Verbo Divino, 1997, p. 544-820. 
COLOP, Luis Sam. Popol Vuh: Traducción al español y notas. Guatemala: F \& G Editores, 2011.

CORTEZ, Otilia. Intertextualidad y paralelismo entre el Popol Vuh y la Biblia. New York: State University, 2010 (recuperado de Biblioteca Virtual Universal. www.Popol\%20Vuh\%20Biblia.pdf p. 11, 27/2/2021)

DARDER, Francesc Ramis. El verdadero Israel, testigo del Dios liberador: itinerario de la vida cristiana a la luz del Pentateuco y los Libros Históricos. Estella: Verbo Divino, 2004.

FALLA, Ricardo. El Popol Wuj, una interpretación para el día de hoy. Guatemala: AVANCSO, 2013. Puede consultarse en:https://cpb-uswww.wpmucdn.com/u.osu.edu/dist/0/34631/files/2016/06/popol-wuj-ricardo-falla2013-1kew523.pdf

MESTERS, Carlos. Sabiduría y Poesía del pueblo de Dios. Estella: Verbo Divino, 2000.

PALMA, Milagros (coord.). Simbólica de la feminidad. Quito: Abya Yala, 1990. RECINOS, Adrián. Popol Vuh, Las antiguas historias del Quiché. Mexico: FCE, 1976.

SILVA, Valmor da. Bater ou não bater nas crianças? Análise a partir dos Provérbios bíblicos. Horizonte, v. 18, n. 55, p. 301-323.

VÍLCHEZ, José. Eclesiastes o Qohelet. Estella, Navarra: Editorial Verbo Divino, 1994.

ZAPATA, John Fredy Vásquez. El banquete de Doña Sabiduría en Prov 9,1-6. Cuestiones Teológicas, Vol. 36, No. 86, 2009, p. 407-433. 